Voix et Images

voixetimages

\title{
Une poésie de la rupture
}

\section{Noël Audet}

Volume 1, numéro 2, décembre 1975

\section{Raoul Duguay}

URI : https://id.erudit.org/iderudit/290082ar

DOI : https://doi.org/10.7202/290082ar

Aller au sommaire du numéro

\section{Éditeur(s)}

Les Presses de l'Université du Québec

\section{ISSN}

0318-9201 (imprimé)

1705-933X (numérique)

Découvrir la revue

Citer ce compte rendu

Audet, N. (1975). Compte rendu de [Une poésie de la rupture]. Voix et Images, 1(2), 289-290. https://doi.org/10.7202/290082ar

Ce document est protégé par la loi sur le droit d'auteur. L'utilisation des services d'Érudit (y compris la reproduction) est assujettie à sa politique d'utilisation que vous pouvez consulter en ligne.

https://apropos.erudit.org/fr/usagers/politique-dutilisation/
Cet article est diffusé et préservé par Érudit.

Érudit est un consortium interuniversitaire sans but lucratif composé de l’Université de Montréal, l'Université Laval et l'Université du Québec à Montréal. Il a pour mission la promotion et la valorisation de la recherche. https://www.erudit.org/fr/ 


\section{Une poésie de la rupture}

Roger Des Roches faisait paraître récemment, à l'Aurore, un nouveau recueil de proses et poésies intitulé Autour de Françoise Sagan indélébile.

Ces textes, assez rares, écrits entre 1969 et 1971, frappent d'abord par les distorsions qu'ils font subir à la syntaxe aussi bien qu'au sémantisme de la phrase ou du vers. Il faut toutefois dépasser cette première opération de brouillage pour accéder au sens. Comme un Mallarmé qui serait surréaliste, Roger Des Roches travaille ses textes jusque dans le moindre détail signifiant, il les tord, les réduit parfois en poussière sonore. «Dire sans métaphores continuelles, mais par accumulations, par contorsions. C'est aussi un jeu ${ }^{1} . "$

Rhétorique en effet de la rupture et de la redondance (aux niveaux phonétique, syntaxique et sémantique), les deux mouvements nécessairement liés pour qu'un sens prenne forme. Cette conception de la littérature m'apparaît caractériser quelques jeunes poètes qui gravitent autour des éditions de l'Aurore. Par des parenthèses soudaines qui désorganisent le sens que l'on attendait et en proposent un autre, par une syntaxe aléatoire où les mots refusent de s'accorder, par des images issues du plus rare filon le plus frêle de l'analogie, Des Roches heurte son lecteur et le travaille en ébranlant à mesure le discours qu'il lui tient. Les structures linguistiques se trouvent remises en question, et, au-delà, les réflexes inconscients qui les supportent en sont troublés.

Gustave largue qu'il mobile

c'est qu'il bave mais qu'os n'a-t-il ni d'arrière

goût : comment ses jardins ont-elles pu croître sans sa mère

1. R. Des Roches, dans Chroniques, vol. I, n ${ }^{\circ} 6-7$, p. 41. 
Les ruptures syntaxiques coupent court à l'élan de la phrase et le texte en sort fortement rythmé, tenu constamment en laisse, maîtrisé sinon écrasé par une volonté d'écriture qui y imprime continuellement sa marque. Par ce biais le lecteur est associé malgré lui à une écriture en train de naître.

Quand on se laisse prendre au jeu cependant, il y a quelque chose de fascinant dans cette circulation de signifiants en liberté surveillée, qui se heurtent et finissent par créer un effet de sens, nébuleuse dure qui produit du sens par la somme mathématique de ses redondances. Si le sens est toujours rendu opaque par la matérialité du langage mise en évidence, il est quand même livré par les recoupements, les retours, les reprises partielles.

Tous les codes s'y trouvent transgressés, du code grammatical au code sexuel, mais en direction de quoi?

Dans une postface très juste, François Charron situe bien les carences politiques habituellement associées à ce genre d'entreprise formelle, non sans montrer par ailleurs le travail relativement efficace qui s'opère dans le champ symbolique.

Comme devant certaines œuvres de musique contemporaine, je ne puis m'empêcher d'adhérer à cet univers de signes désarticulés selon les perceptions du moment (mythification de détails réalistes) tout en regrettant l'absence d'un principe externe ou d'une vision qui redonnerait à ces pulsions désorganisatrices leur pleine efficacité esthétique et politique.

Noël Audet 